\title{
A Philosophy of Informing Science
}

\author{
Eli B. Cohen \\ Informing Science Institute, Santa Rosa, CA, USA \\ EliCohen@InformingScience.org
}

\begin{abstract}
Informing Science is the transdiscipline that studies all issues in informing clients. In recent decades, advances in information technologies magnify the impact and importance of this transdiscipline on many fields of study. Yet transdisciplinary research conducted to date tends to be fieldspecific and not well informed by the works conducted in other fields that are also within this same transdiscipline.

This paper provides additional context and so updates the content of the Cohen (1999) paper, the seminal work on Informing Science. This paper describes the Informing Science Philosophy of conducting research that crosses disciplinary boundaries. It also points out the need for colleagues from the diverse disciplines, each dealing with issues in informing clients, to communicate with and learn from one another.
\end{abstract}

Keywords. Informing, transdiscipline, metaphors, informing science, frameworks

\section{Introduction}

The transdiscipline of Informing Science, as introduced by Cohen (1999), explores how best to inform clients using information technology. Thinking and researching in Informing Science has expanded in the last decade. The journal Informing Science: an International Journal of an Emerging Transdiscipline is in its twelve year of publication and the journal Issues in Informing Science and Information Technology is in its sixth. A Google search for the phrase "Informing Science" now brings up over 38,000 hits.

The evolving transdiscipline involves various reference disciplines including psychology, computer science, evolutionary biology, and linguistics. Disciplines that use Informing Science are diverse: included are education, government, business, public relations, and dozens more.

The essence of the Informing Science philosophy is the transfer of knowledge from one field to another: breaking down disciplinary boundaries that hinder the flow of knowledge.

This paper aims, first, to show the evolving importance of Informing Science. It also points out areas of research that need further exploration and the need for refinement of the Informing Sci-

Material published as part of this publication, either on-line or in print, is copyrighted by the Informing Science Institute. Permission to make digital or paper copy of part or all of these works for personal or classroom use is granted without fee provided that the copies are not made or distributed for profit or commercial advantage AND that copies 1) bear this notice in full and 2) give the full citation on the first page. It is permissible to abstract these works so long as credit is given. To copy in all other cases or to republish or to post on a server or to redistribute to lists requires specific permission and payment of a fee. Contact Publisher@InformingScience.org to request redistribution permission. ence framework.

\section{Informing through Metaphors}

This paper makes use of a number of metaphors to describe and explain its points. This is nothing new. Goschler (2007) writes about how metaphors inform and impact scientific thinking. This use fits particularly well with the 
Informing Science philosophy that knowledge developed in and for one area of study often enlightens inquiry in other disciplines

The term "metaphor" can be used to mean several related things. Here we are following the linguistic (not grammatical) meaning as a method of applying existing knowledge of how things relate (cognition) to create an understanding of new situations. That is, it is a method that transfers ways of thinking and/or applies existing knowledge to new and different situations. (See Lakoff and Johnson $(1980,1999)$ for a more detailed discussion of how linguists use the term "metaphor" and Schunk (2004) on its uses in education.)

\section{Exploring with Lasers and Lanterns}

The first metaphor to help us better understand the Informing Science philosophy is the laser beam and the lantern (adapted from Cohen, 2007b). As we know, a laser provides a highly focused, narrow beam of illumination that stretches to great distances. In contrast, the lantern, while it may provide the same amount of illumination in total, lights up a broad area. It is purposefully unfocused, and so its brightness diminishes exponentially at distances from the source.

The laser and the lantern each has its own qualities and uses. The lantern is best at enlightening interrelationships of nearby objects. For this reason we likely would choose a lantern for illumination if walking on a dark path through the wood. But if we wanted to look far into the dark woods, we likely would choose a laser or other highly focused beam of light.

There is no one single best source of illumination. Both lasers and lanterns have their uses.

We can apply this metaphor to research as conducted in traditional universities. When we do, we note a problem. Only "laser" research is fully rewarded on campuses. Here is what I mean by that. Traditional universities (in the US, anyway) are organized into colleges or schools. Each college is composed of various departments. Figure 1 pictorially shows such a silo organization.
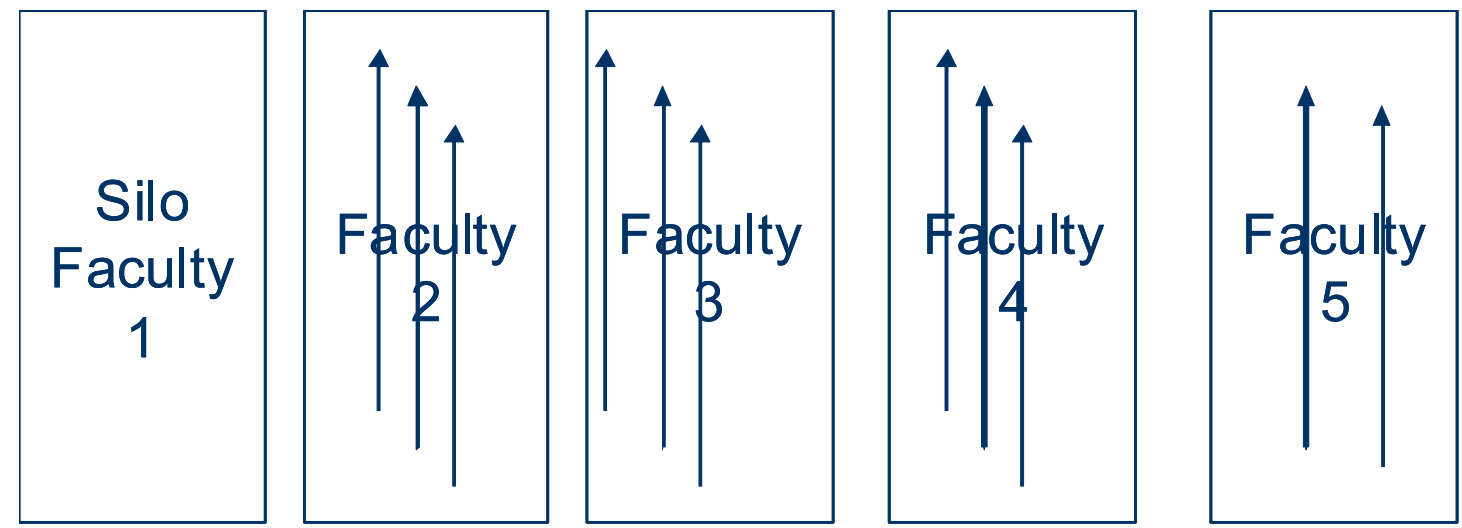

Figure 1. Laser research (shown by arrows) is narrow; lantern research is broad and often crosses disciplinary boundaries

Professors receive their rewards (paychecks and raises) based on their activities in support of their own department (and school). The most prized (and rewarded) research is conducted on topics specific to one's own department. Research conducted in other areas, even if in collaboration with colleagues from other faculties, is not viewed as valuable as research entirely within one's own department's field. (Indeed, graduate students may find it difficult to find a research advisor if their research is different than that already being conducted in the department.) Such prized research is "laser" research. It builds on and extends the narrow focus of research already considered legitimate. 
Therefore, the traditional university structure leaves unrewarded "lantern" research that illumines fields that extend beyond one's own department. In this way, research addressing the so-called wicked problems of the world (Rittel \& Webber, 1973) is left relatively unrewarded since these problems cross disciplinary boundaries. Yet for many, including me, they are the most interesting exactly because they defy simple, discipline-specific solutions.

\section{Over Time, Disciplines Have Evolved}

While it is true that traditional university departments (typically designed around one or a few disciplines) do get reorganized from time to time, such change typically is due to non-academic reasons (such as the need to rebalance workload or to reflect the capacity limits of the building that houses the department's offices). Separate from these administrative changes are more dramatic changes occurring to the actual disciplines within departments. Across the university, disciplines have evolved and are evolving in response to changes in technology, including information technology. Some disciplines change, some new ones are born, while still others slowly wither toward extinction.

We can track much of the source of this evolution to technological changes. Consider how newspaper and journal publishing has changed within our lifetimes in response to the web and printon-demand technology, including home and office printers. Similarly, retail sales, including bookstores, are undergoing dramatic change. The world-wide web has enabled sales to remote customers but also brought competition from remote locations.

Even though disciplines have evolved to take advantage of advances in information technologies, outdated disciplinary biases remain as to what each field is and is not. The story/metaphor of the elephant and wise men helps us understand these biases.

\section{Professors describing an elephant in various ways}

An old story from India, told in various forms, relates how when blind men each touch a different part of an elephant (the tusk, leg, side, trunk, or tail), they each understand the elephant differently, each with complete confidence, but with only partial truth ("Blind men and an elephant," n.d.). So too it is with typical university field-based research. Our field's training and assumptions impose upon us as researchers a bias that blinds us to other elements of that which we are studying.

Like the elephant, reality is complex with many different elements, all of which are true but each of which is only part of the whole truth; therefore informing clients about reality is complex. To reduce this complexity, disciplinary fields focus on specific features and ignore or at least diminishing other features of reality. This bias in deciding which features are important and which are not is necessary, but it is bias. We can see only what we look at and focus upon (and not other things). (It is a human capacity limitation or fragility that is the source of bias. See Gill (2008a, p. 230) for a list of such biases.)

For this reason, when information science researchers view informing, they see only information science. When computer science professionals view informing, they too see it as but a part of their field. The same is true for information systems professionals, and so on. Their biases make it difficult for them to see that Informing Science is more than just what they study. Let us explore the idea further using the metaphor of the ugly duckling.

\section{Ugly Duckling: Evolved Disciplines that Study Informing Science}

Danish author Hans Christian Andersen wrote the tale The Ugly Duckling (Andersen, 1843/1949) about a cygnet (young swan) ostracized by ducklings because he was different. Cohen (1999) uses this metaphor to convey how Informing Science, while different from other disciplines, has a 
beauty of its own. It is not just an imperfect version of MIS, library science, or education, for example.

Indeed, many fields confront the challenge of informing clients, a challenge often made more difficult when information technology is employed. Examples include the following:

- MIS informs business clients,

- Library Science informs library patrons,

- Medicine informs medical workers and patients,

- Communications and Rhetoric inform the public,

- Government informs citizens,

- Education informs the student,

- and so on.

Because they are focused on their own field, when researchers in these fields look at Informing Science they tend to see it as just an imperfect way of viewing their own discipline. Yet, Informing Science is a tool to solve the problem shared by these fields: how best to inform clients. In this way it has a beauty of its own, as does the swan.

\section{Same words, but different foci}

Even though various fields claim "IS" as their own, they fail to realize that they are using the term to mean different things. The disagreement on the meaning of "IS" is due to cultural bias, that is the hidden assumptions that define which topics are interesting and acceptable for research.

- The focus of research for an "Information Scientist", that is from the school formerly known as Library Science, is the information seeker. (Kuhlthau, 1991)

- The focus of research in informatics and Management Information Systems is the information system (that it needs to create for the user).

- For the researcher from a technology school involved with informing clients, such as from computer science or applied computer science, the focus is the technology to provide a solution. No matter what the problem, technology is the solution.

- The focus for those involved in Intelligence (Military, Government, Business) is information gathering and analysis. Intelligence services includes credit reporting agencies

\section{Same words, but different meanings}

Even within the same field, in this instance Management Information Systems, researchers use the same words, but have different definitions. Evaristo and Karahanna (1997) note that IS research as conducted in North America is qualitatively different from IS research conducted in Europe, both in focus and in epistemology. The term is used to mean different things yet these researchers are from the same field!

Informing Science is the union of aspects of these disciplines, the aspects that relate to informing clients. Its purpose is to inform these disciplines. By union, I mean more than just summing all the work. There is synergy in bringing together researchers from diverse fields to bear on the common problem of how best to inform clients. 


\section{Informing Science as an Evolutionary Idea}

As noted above, academic disciplines are evolving. Russian-American cybernetician Valentin Turchin (1977; Turchin \& Joslyn, 1999) posits metasystem transition as a process by which organisms evolve. The author of this paper perceives that many disparate fields are evolving from separate entities into something greater, organized around common problems, such as the problem of how best to inform their client. More and more universities are recognizing this evolution by reorganizing apparently dissimilar departments into schools and colleges of information studies. This is a good first step.

\section{Many of Today's Problems are Transdisciplinary in Nature}

With apologies for stating the obvious, note that the reason that Informing Science and other transdisciplines are needed is that the many of today's most interesting problems are transdisciplinary in nature. The current silo research focus is ill-equipped to deal with such problems. Grandon Gill (2008b) argues that many of the types of informing problem that we are attempting to address today involve achieving fit between components that are quite complex in their interdependencies. Understanding how fit is achieved when humans are involved may draw from a myriad of disciplines including, for example, psychology, communications, management, and computer science, as well as many other fields related to the specific task. Such problems often exhibit decomposable components as well as components that cannot be examined independently. Gill and Sincich (2008) further note that while the departmental approach to research may work reasonably well at exploring the decomposable elements - what they call the "low-hanging fruit"-it will invariable fail in its efforts to understand the non-decomposable elements. Even worse, it can easily be misled by statistical anomalies that result when a deep understanding of the processes is not present. Only a transdisciplinary approach, bringing together the expertise of all the disciplines relevant to a particular problem, offers any real hope of furthering our understanding. That is, for many problems, we need to examine the entire forest, not just this tree or that.

\section{Informing Science: The Whole is More than the Sum of Its Parts}

If we were to study only this tree and that tree, we would miss seeing the forest, for it is more than just trees. Forests also contain birds and animals and insects, vital for its well-being.

Likewise the elephant is more than a leg, trunk, tail, side, tusk, and such. It has parts that the blind men did not examine and they all interrelate. Similarly, informing too is more than the sums of its individual parts.

The late philosopher Stafford Beer pointed out that Informing Science is a transdiscipline. Philosopher Michael Scriven (2008) defines a transdiscipline as a discipline that serves many other disciplines as a tool (Figure 2). For example, modern statistics, developed to assist the study of agriculture or of mortality (depending on the source cited) is now used in the study of psychology, business, and countless other disciplines that employ experimentation. 


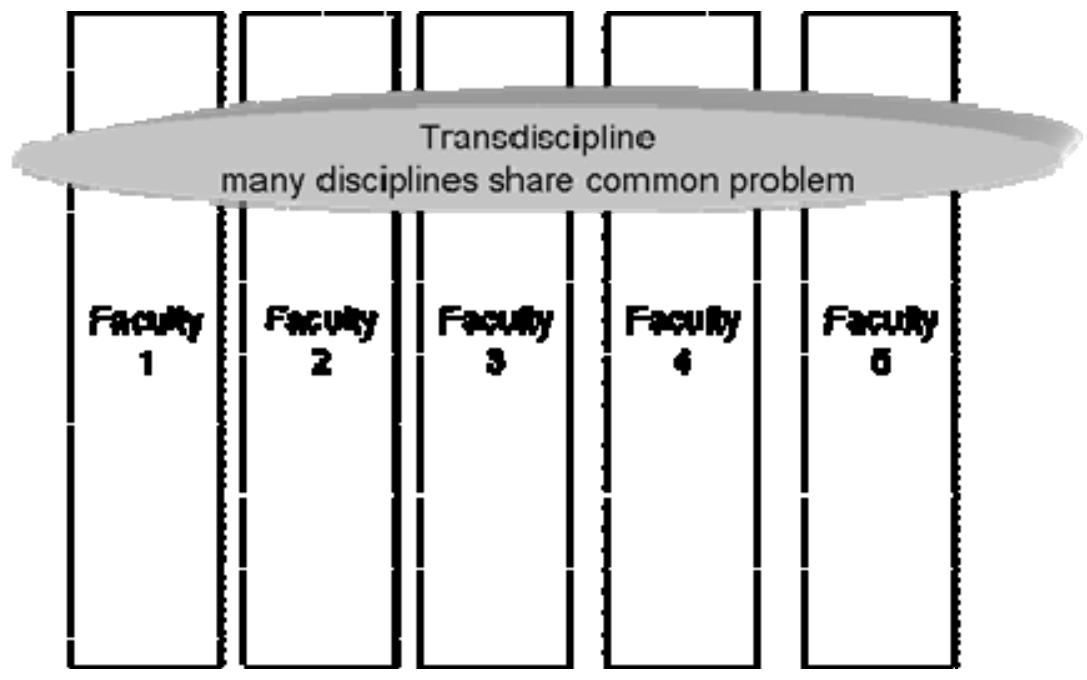

Figure 2. A transdiscipline is a coherent set of research topics that are shared by several distinct academic disciplines.

(Universities are not yet well organized to reward transdisciplinary research.)

\section{Sentence Definition of Informing Science}

Building on the work of Mason and Mitroff (1973), Cohen (1999) provided the following sentence definition of Informing Science:

The fields that comprise the transdiscipline of Informing Science

- provide their clientele with information

- in a form, format, and schedule

- that maximizes its effectiveness.

Understanding of each of the keywords of this sentence, such as clientele, information, form, format, schedule, effectiveness, can and should be expanded through research and so this sentence definition serves as a platform for research.

This sentence definition provides a simple means for describing Informing Science. It is easy to understand and to express. But its simplicity comes at the price of obscuring some of the more interesting complexities of Informing Science, such as the following:

1. Biological and psychological issues in how clients attend, perceive, and act on information provided,

2. The decision-making environment itself, including its sociology and politics,

3. Issues involving the media for communicating information,

4. Error, bias, misinformation, and disinformation in informing systems.

The point here is that a simple sentence definition is very practical and helpful in communicating but should not be used to limit the transdiscipline. The simple definition implies areas that need to be made more explicit through study. Hence, we should use more concrete frameworks in developing the transdiscipline. 


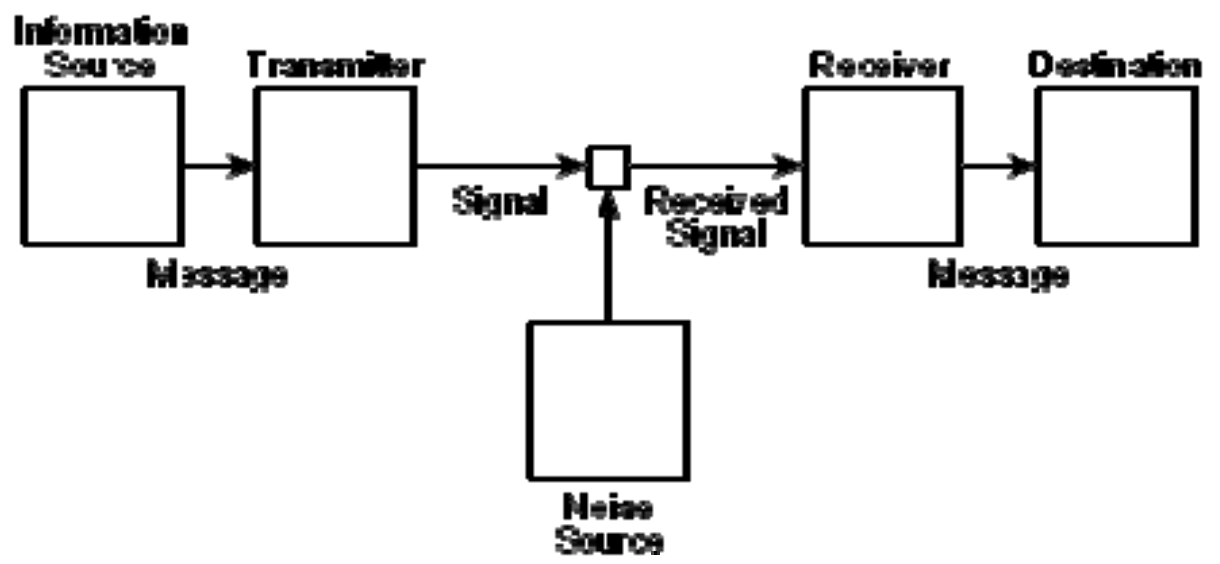

Figure 3. The "simple" presentation of the Shannon-Weaver (1949) Model for Communications. At the center of this model are the technologies involved in communications and their mathematical representations.

Source: http://upload.wikiMEDIA.org/wikipedia/commons/f/f3/Shannon_communication_system.svg downloaded September 1, 2008. WikiMEDIA drawings are in the public domain.

\section{Cohen's Informing Science Framework}

In its most explicit, the Informing Science framework can be seen as both an extension and a special instance of the communications conduit model (or conduit metaphor), first proposed by Shannon and Weaver (1949) and adapted for use in linguistics by Reddy (1979). A simple rendering of that model (without the mathematics) is shown as Figure 3.

The Informing Science framework is also a special instance in that it draws from T. D. Wilson's 1981 model of information seeking behavior (Wilson, 1981; see also Wilson, 1999, 2000). As Figure 4 shows, that model points out the layers of complexity and barriers in information seeking, as explained below.

What's new? The Informing Science framework can be seen as an extension of these models.

Context of Information Need

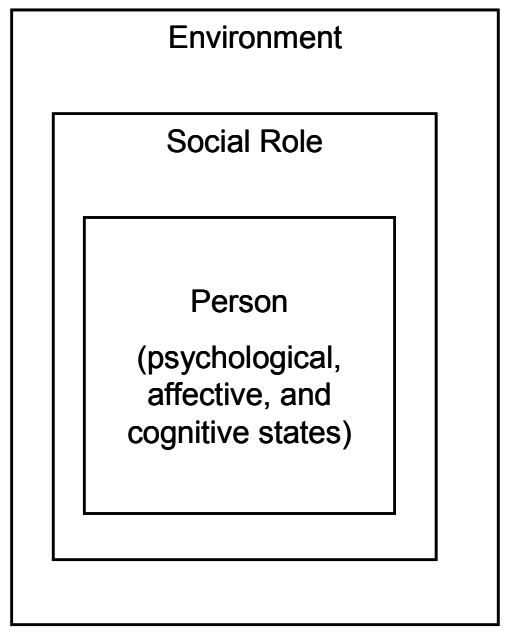

Figure 4: One component of T. D. Wilson's (1981) model of information seeking behavior.
The extensions include explicit understanding of the limitations, that is, the "fragility" of the informer, the channel (including encoding for transmission across media and resultant decoding, all in the presence of noise), and the information client. These fragilities include (but are not limited to) human limitations in perception and processing, biases due to prior knowledge, skills, abilities, and information format preferences. Likewise, the information technology channel imposes its own set of limitations and biases.

To be clear, both Shannon and Weaver and Reddy understood that problems of communication are on three levels:

- technical: accuracy in relaying information

- semantic: correctness in conveying meaning

- effectiveness: the received meaning effects behavior 


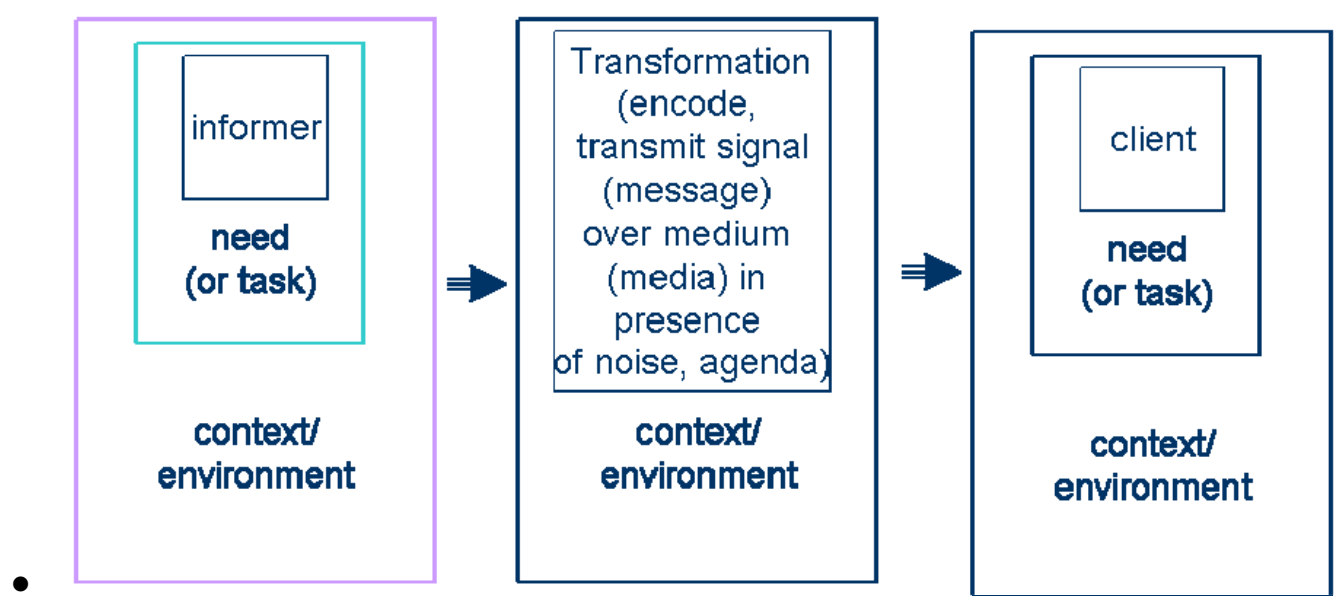

Figure 5. This rendering of the Informing Science framework includes the ShannonWeaver model and the Wilson model, focusing the reader's attention on the components of informing clients, including the needs and human fragilities of both the informer and the client. It also points out that the medium or media exists within a context and environment.

However, Shannon and Weaver focused their research on the technical level. Wilson focused his attention on semantic and effectiveness levels.

The revised, Informing Science conduit framework is seen as Figure 5. This figure expands the contextual environment of the informer, information transmission and receiving media, and receiver of information. It explicitly acknowledges that they exist within complex environments that greatly impact them. For example, the entity being informed is influenced by its own psychological and physiological fragilities and operates within task requirements (and anticipations), all of which exist within and are influenced by environmental context.

It may be argued whether the need (or task) is within the context (environment) or visa versa. Likewise, T. D. Wilson's 1981 model places environment within the context and, for simplicity, the Informing Science framework combined these two elements. Regardless of these details (which need to be tested experimentally as well as logically), both frameworks agree that information needs of an individual are complex and are a function of context, environment, social or job role or task, and the individual's psychology.

Since both the informer and the client are influenced by human-related issues, they are best examined by those fields of study that deal with understanding cognitive, behavioral and social issues. Similarly, one might expect the technological concerns shown in the middle of the diagram to be studied by those who study technological issues.

The framework draws attention to the informer and the client, explicitly pointing out the need to study the environment and context of each, their tasks, and what we call their fragility. This paper uses the term fragility to refer to the cognitive limitations of human processing of information. A vast amount of literature already exists on the technological elements that must occur to get a message from one point to another across one or more media. This framework focuses attention on the other, less studied areas of Informing Science.

Is this framework complete? Of course not. It is useful as a step in developing a better framework and ultimately a model that has predictive value. 

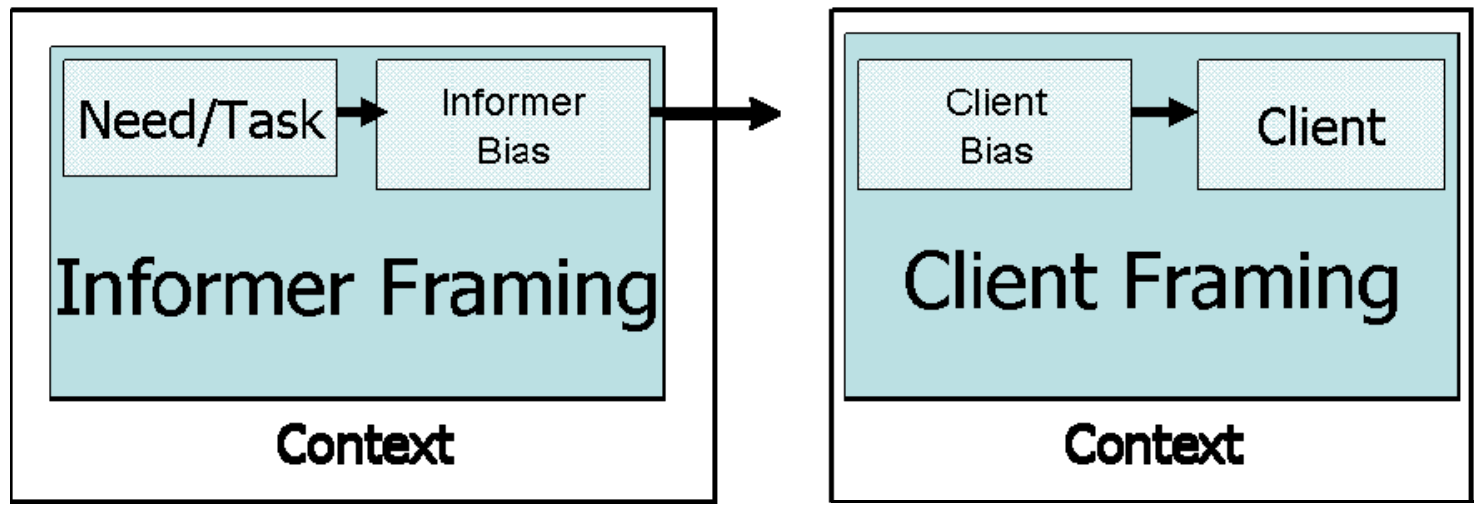

Figure 6. The Framing phenomenon can be viewed within the Informing Science framework as the way in which the informer creates the message in view of the informer's need or task and bias and the client interprets the message in terms of his/her own need or task and bias.

While this framework is helpful, it still leaves several important topics un-delineated. For example, what does it mean to "inform a client"? Is it merely providing information or does it involve more? For example, does the information provided need to influence behavior (such as decisionmaking behavior) for "informing" to have occurred. In a decision-making environment, does the information need to reduce risk? How can these things be measured?

Also, the conduit metaphor of Figure 3 has been criticized in that it contains tacit assumptions that the informer and client are "playing the same game," that is, both sender and receiver are using the same master metaphor. The same criticism need not apply to the framework in Figure 5.

This idea of "playing the same game", or context in which the information exists includes the concept of framing (Tversky \& Kahneman, 1981). Tversky and Kahneman demonstrated over a multitude of experiments that the behavior of the "client" depends not only on the information transferred from the informer, but also on the context, or frame, in which the information is transferred. Figure 6 shows the relevant portions of Figure 5 that deal with framing. When the sender initiates informing, s/he has a particular frame in mind. Similarly, the client selects (perhaps unconsciously) the interpretation frame. Informing breaks down when there are fundamental differences between the frames.

Lastly, it is very important to understand that the framework presented in Figure 5 is but one of many such frameworks proposed for the study of Informing Science. Many others appear on the pages of the journal Informing Science. This framework is meant to help guide research, not to define or limit the transdiscipline.

While the framework currently does address bias, it is not well suited in its present form to address the issues of misinforming and disinforming. By misinforming, I am referring to systems that by mistake provide incorrect or misleading information. Examples of misinforming systems abound. Anyone using an automobile routing GPS system knows this when the system occasionally routes the driver on the wrong course. Disinformation is the intentional providing the client with wrong information. A child who claims to the teacher that the dog ate his or her homework provides disinformation; military forces in wartime employ disinformation against the enemy.

\section{Areas for Further Research}

The Informing Science framework provides a basis for identifying areas that are likely to be important in future research. In general, each individual research activity is likely to emphasize on one of the four key elements of Figure 5: the informer, the client, the task or need driving the informing process or the channels through which informing takes place. At the same time, recog- 
nizing the system-driven nature of informing processes and given the transdisciplinary makeup of Informing Science, such research will also necessary consider the implications of its findings for the system as a whole. Let us now consider examples of topics drawn from each of the four areas. Again, these are only examples and are not meant to limit the transdiscipline and it development.

\section{Informer-Focused Research: Bias, Misinformation, and Disinformation in Informing Systems}

The assumption behind all the theories and practice as taught in university is that information systems produce information. Little if any attention is given to bias, misinformation, and disinformation in information systems. What little attention that is given typically is confined to computer crime and accounting.

Cohen (2000a, 2000b, 2007a) has addressed the issue, at least in rudimentary ways. Those papers assert that bias is inherent to all information systems due to the need to select which data to summarize, analyze, and report. Bias, misinformation, and disinformation are present, but not well researched or reported in information systems. Cohen's papers view (computerized) information systems as a subset of informing systems and point out that much attention has been given to bias, misinformation, and disinformation in their broader contexts of journalism (for example, "Fox News Channel controversies," n. d.; Hoffman \& Wallach, 2007) and the military. Stahl (2006) provides a critical perspective on the differences among information, misinformation, and disinformation.

(Bias is also present in the channel and in the client. The point here is to recognize bias in the informer.)

\section{Client-Focused Research: Cognitive and Physiological Elements of Informing}

Another area in which the framework needs development is in the explication of the cognitive and physiological elements of informing. As alluded to above, it is obvious that a full understanding of informing systems is beyond the scope of any one field. Those whose backgrounds are in building computer system are unlikely to understand fully the behavioral issues involved in informing people. Indeed, recent research findings indicate that we cannot blindly accept the assumption that clients behave rationally. Cognitive psychologists demonstrate that people have cognitive limitation (for example, Ariely, 2008). Brain scientists find neurological, chemical, and hormonal contributions to behavior and decision making (Burton, 2008; see also Levitan, 2006). Social psychologists and sociologists have contributions to add to the context in which decision making takes place (for examples, see Brafman \& Brafman, 2008; Gladwell, 2002, 2005). Even economists contribute to understanding how people make decisions (for example, see Hartford, 2008). Therefore, this paper suggests that Informing Science includes the psychological, sociological, and physiological contexts in which people receive and process information. We will call this intersection of cognitive science with issues of informing cognitive informatics and hope that giving name to it will encourage additional research into the field.

\section{Task/Need Focused Research: Complex versus Routine Informing}

The presence of complexity can dramatically impact the nature of the process required to achieve effective informing (Gill \& Cohen, 2008). Where tasks or needs are relatively routine and unchanging over time, we can expect that well-tuned informing systems can be designed to achieve efficient informing. A useful means of looking at these systems is in terms of three levels: 1) the informing instance level, where actual informing takes place, 2) the instance-creation level, where 
new informing instances are created, and 3) the design level, where general patterns for informing are established (Cohen, 1999). As complexity grows, however, distinctions between levels are likely to blur and new patterns of informing and informing system evolution are likely to be required. Because the problems of dynamic complexity often fall outside the domains of existing disciplines (i.e., highly complex informing often falls outside the domain that is possible with existing information technologies, education typically does not study communicating content that is non-routine to both informer and client), it represents an important opportunity for the Informing Science field.

\section{Channel-Focused Research: Informing Networks}

Figures 5 and 6 convey the impression that informing takes place between a single informer and a single client through a single channel. In practice, however, senders and clients can both be collections of agents - often heterogeneous in key characteristics (e.g., motivation and prior knowledge) - and a variety of channels may be employed. To date, a great deal of research has been conducted related to the impact of heterogeneity on informing (e.g., Gladwell, 2002; Rogers, 2003). In addition, an exciting stream of research now focuses on how informing networks emerge and behave (e.g., Barabasi, 2003; Watts, 2003). Important discoveries remain to be made regarding how such networks are impacted by other characteristics of the informing context, such as the underlying task/need driving the informing process and how informer/client characteristics impact the process and its evolution. Here, once again, the transdisciplinary nature of Informing Science places the field in an ideal position to make important contributions in these areas.

\section{Challenges to Research}

There are a number of challenges to this transdisciplinary research, most of which are pragmatic in nature. These challenges include the need to change the reward structure of the traditional university and the need for opportunities to learn from the work, research, and needs of colleagues in other fields. The following are some steps that have been taken to meet these challenges and some that still taking.

\section{Need for Journal}

Research is unlikely to be conducted if the results would have no outlet for dissemination. After all, university's researchers are rewarded more for research that is published than for unpublished research. This could be a problem given the transdisciplinary nature of the research and the missions of legacy journals.

Journals typically limit what articles they will accept and publish according to their mission. The reader may see the problem here. Journals publish papers only within their scope; legacy journals follow the same disciplinary framework that has so successfully kept academicians in government, medicine, business, and the military from learning one from the other.

Therefore, there was a need for a transdisciplinary field of inquiry dedicated to the Informing Science to disseminate relevant research findings. Other transdisciplines have employed a similar approach. For example, the transdiscipline of statistics has numerous journals; in fact, statistics education alone has at least five journals devoted to the topic (Journal of Statistics Education, n.d.).

\section{Need for Conference}

Face-to-face interpersonal communications is required (or at least highly desirable) to build trust (Guadagno \& Cialdini, 2007). Trust is necessary in any collaborative research, but particularly so with transdisciplinary research. It may require working with colleagues from other locations and 
countries, but also from other disciplines and, consequently, using epistemologies new to the researcher. Can such research be encouraged and promoted? The organizers of the Informing Science Conference (http://InSITE.nu) thought so and therefore hold an annual conference that not only presents research from diverse fields but specifically fosters trust-building interactions through shared dining and similar networking opportunities and activities.

A second reason for face-to-face meetings with colleagues from different fields is to make tacit knowledge explicit (Polanyi, 1997). As noted above, even colleagues in the same field (but from different backgrounds) commonly use the same words to mean different things.

\section{Researchers Teaching Teachers Research; Teachers Teaching Researchers Teaching}

An informal analysis of the articles appearing in transdisciplinary journals and the Informing Science conference mentioned above provides ample illustration to the benefits of researchers in one field teaching researchers trained in different fields about their own research methods and epistemologies. For example, a single article may draw upon the research traditions of philosophy, information systems, education and pedagogical science, and sociology, to name of few. New areas of research are being explored, perhaps because there is now a place for disseminating knowledge developed through this research. That is, even with researchers sequestered in their own academic silos, the Informing Science journal and its conference allows and encourages them to research together and learn from one another on common areas of interest.

\section{Reward Structure}

The typical traditional university does not have a reward structure to encourage research toward solving wicked and other pressing trandisciplinary problems. What is needed is for the university to recognize and reward the reunification of knowledge (overcoming artificial barriers imposed by administrative departments). Unfortunately, in most instances cross-disciplinary research is not rewarded as much discipline-specific research.

One solution to this problem is to reward generalists by recognizing lantern research as a specialty. In medicine, this was done by providing general practitioners with their own specialty, Internal (or Family) Medicine.

\section{Summary of Philosophy}

In summary, the Informing Science philosophy is that broad, transdisciplinary research is needed to understand how best to use technology to inform clients. Because many disciplines have evolved due to changes to technology, they need a better understanding of this transdiscipline. Yet, these disciplines have in the past been reinventing the wheel, unaware that colleagues from other disciplines are already working on the same problem. The Informing Science philosophy is to break down barriers that limit the exploration of this important topic.

Much work already has done in diverse fields, and colleagues need to benefit from crossfertilization of their disciplines with others. The complex phenomenon of informing clients is best studied through diverse epistemologies so as to reduce disciplinary bias.

All the blind men reported their research with complete truth and accuracy, yet individually they understood very little of the elephant. 


\section{References}

Andersen, H. C. (1949). Den grimme Ælling (The Ugly Duckling). In J. Hersholt (Trans.), The Complete Andersen. New York: The Limited Editions Club. (Original work published in 1843.) Retrieved November 20, 2008, from http://www.andersen.sdu.dk/vaerk/hersholt/TheUglyDuckling_e.html

Ariely, D. (2008). Predictably irrational: The hidden forces that shape our decisions. New York: HarperCollins.

Barabasi, A. L. (2002). Linked. New York, NY: Plume.

Blind men and an elephant. (n.d.) Retrieved November 30, 2008, from http://en.wikipedia.org/wiki/Blind_Men_and_an_Elephant

Brafman, O., \& Brafman, R. (2008) Sway: The irresistible pull of irrational behaviour. New York: Doubleday.

Burton, R. A. (2008). On being certain: Believing you are right even when you are not. New York: St. Martin's Press.

Cohen, E. (1999). From ugly duckling to swan: Reconceptualizing information systems as a field of the discipline informing science. Journal of Computing and Information Technology, 7(3), 213-219.

Cohen, E. (2000a). Informing and misinforming [Invited keynote address]. 1st International Congress of the OOICTL Academy on Teaching, Learning \& Classroom/Course Management In Business And Related Areas, Shreveport, Louisiana, September 17-22, 2000

Cohen, E. (2000b). Failure to inform: Errors in informing systems. Proceedings of the 2000 Americas Conference on Information Systems (AmCIS 2000), August 10-13th, 2000, Long Beach, California, $p$ 1057-1061

Cohen, E. (2007a). Informing and misinforming: The practice and science of using technology to inform, misinform, \& disinform. Israel Association for Information Systems 2007 Conference: Bar-Ilan University, May 2007.

Cohen, E. (2007b). The laser and the lantern: The many roads to IT education and the need for new paths for computing qualification. Keynote address at the Annual Conference of the National Advisory Committee on Computing Qualifications, Nelson, New Zealand, July 2007.

Evaristo, J. R., \& Karahanna, E. (1997). Is North American IS research different from European IS research? Database, 28(3), 32-43.

Fox News Channel controversies. (n.d.). Wikipedia. Retrieved 8/14/08 from http://en.wikipedia.org/wiki/Fox_News_Channel_controversies

Gill, T. G. (2008a). A psychologically plausible goal-based utility function. Informing Science: The International Journal of an Emerging Transdiscipline, 11, 227-252. Retrieved from http://inform.nu/Articles/Vol11/ISJv11p227-252Gill220.pdf

Gill, T. G. (2008b). Reflections on researching the rugged fitness landscape. Informing Science: The International Journal of an Emerging Transdiscipline, 11, 165-196. Retrieved from http://inform.nu/Articles/Vol11/ISJv11p165-196Gill219.pdf

Gill, T. G. \& Cohen, E. (2008). Research themes in complex informing. Informing Science: The International Journal of an Emerging Transdiscipline, 11, 147-164. Retrieved from http://inform.nu/Articles/Vol11/ISJv11p147-164GillIntro.pdf

Gill, T. G. \& Simich, T. L. (2008). Illusions of significance in a rugged landscape. Informing Science: The International Journal of an Emerging Transdiscipline, 11, 197-226. Retrieved from http://inform.nu/Articles/Vol11/ISJv11p197-226Gilllllusions.pdf

Gladwell, M. (2002). The tipping point. New York: Little, Brown, and Company.

Gladwell, M. (2005). Blink: The power of thinking without thinking. New York: Little, Brown, and Company 
Goschler, J. (2007). Metaphors in cognitive and neurosciences. Which impact have metaphors on scientific theories and models? Metaphor in Science and Technology, 12, 7-20. Retrieved from http://www.metaphorik.de/12/goschler.pdf

Guadagno, R. E., \& Cialdini, R. B. (2007). Persuade him by email, but see her in person: Online persuasion revisited. Computers in Human Behavior, 23, 999-1015.

Hartford, T. (2008). The logic of life: The rational economics of an irrational world. New York: Random House.

Hoffman, A. J., \& Wallach, J. (2007). The effects of media bias. Journal of Applied Social Psychology, $37(3), 616-630$.

Journal of Statistics Education. (n.d.). Retrieved October 8, 2008, from http://www.amstat.org/PUBLICATIONS/JSE/

Kuhlthau, C. C. (1991). Inside the search process: Information seeking from the user's perspective. Journal of the American Society for Information Science. 42(5), 361-371. Retrieved December 1, 2008, from http://www.scils.rutgers.edu/ belkin/612-05/kuhlthau-jasist-91.pdf

Lakoff, G., \& Johnson, M. (1980). Metaphors we live by. Chicago: University of Chicago Press

Lakoff, G., \& Johnson, M. (1999) Philosophy in the flesh: The embodied mind and its challenges to western thought. New York: Basic Books.

Levitin, D. J. (2006). This is your brain on music: The science of a human obsession. New York, NY: Penguin.

Mason, R. O., \& Mitroff, I. I. (1973). A program for research in management information systems. Management Science, 19(5), 475-485.

Polanyi, M. (1997). Tacit knowledge. In L. Prusak, Knowledge in organizations (Chapter 7). ButterworthHeinemann.

Reddy, M. J. (1979). The conduit metaphor: A case of frame conflict in our language about language. In A. Ortony (Ed.), Metaphor and thought (p. 284-297). Cambridge: Cambridge University Press.

Rittel, H., \& Webber, M. (1973). Dilemmas in a general theory of planning. Policy Sciences, 4, 155-169. Retrieved December 8, 2008, from http://www.botanischergarten.ch/Discourse/Rittel-Dilemmas2005.pdf

Rogers, E. M. (2003). Diffusion of innovations (5th ed.). New York: Free Press.

Schunk, D. H. (2004). Learning theories: An educational perspective (4th ed.). Upper Saddle River, NJ, USA: Pearson.

Scriven, M. (2008) Transdiscipline. EvaluationWiki. Retrieved September 26, 2008, from http://wiki.eval.wmich.edu/wiki/Transdiscipline

Shannon, C. E., \& Weaver, W. (1949). The mathematical theory of communication. Urbana, Illinois: The University of Illinois Press.

Stahl, B. C. (2006). On the difference or equality of information, misinformation, and disinformation: A Critical research perspective. Informing Science: The International Journal of an Emerging Transdiscipline, 9, 83-96. Retrieved 10/8/08 from http://inform.nu/Articles/Vol9/v9p083-096Stahl65.pdf

Turchin, V. F. (1977). The phenomenon of science: A cybernetic approach to human evolution. New York, NY: Columbia University Press.

Turchin, V. F., \& Joslyn, C. (1999). The metasystem transition. Retrieved 8/31/08 from Principia Cybernetica Web: http://cleamc11.vub.ac.be/MST.html

Tversky, A., \& Kahneman, D. (1981). The framing of decisions and the psychology of choice. Science, 211(4481), 453-458. American Association for the Advancement of Science.

Watts, D. J. (2003). Six degrees: The science of a connected age. New York, NY: Norton. 
Wilson, T. D. (1981). On user studies and information needs. Journal of Documentation, 37(1), 3-15.

Wilson, T. D. (1999). Models in information behavior research. Journal of Documentation, 55(3), 249-270. Retrieved December 1, 2008, from http://informationr.net/tdw/publ/papers/1999JDoc.html

Wilson, T.D. (2000). Human information behavior. Informing Science: the International Journal of an Emerging Transdiscipline. 3(2), 49-56. Retrieved December 1, 2008, from http://inform.nu/Articles/Vol3/v3n2p49-56.pdf

\section{Biography}

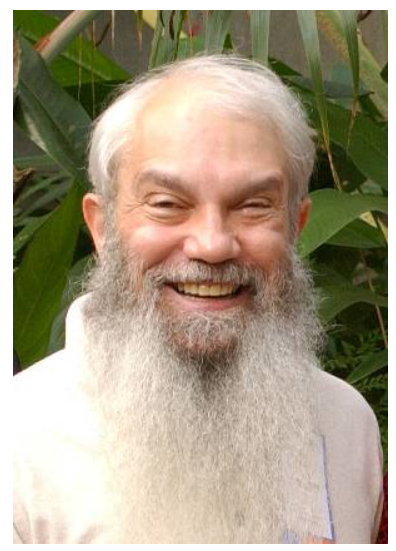

Eli Cohen founded the Informing Science Institute (ISI), an international organization of over 500 members from over 60 countries. The institute publishes eight journals and several dozen books, all of which are available online to everyone without charge (as well as in paper format). The organization holds one or more international conferences each year. ISI is an organization of colleagues mentoring fellow colleagues. It draws together people who teach, research, and use information technologies to inform clients (regardless of academic discipline) to share their knowledge with others.

Dr Cohen's background is multi-disciplinary. He holds degrees in and has published research in Management Information Systems, Psychology, Statistics, Mathematics, and Education. He has taught in Poland, Slovenia, South Africa, Australia, and the US. In addition, he has conducted seminars in a large number of countries, including Fiji, New Zealand, Australia, Hong Kong, Singapore, Malaysia, Thailand, and Cyprus. 